\title{
Assessment of neonatal mortality in the Neonatal Intensive Care Unit in Sabzevar City for the period of 2006-2013
}

\author{
Bibi Leila Hoseini ${ }^{1}$, Zahra Miri Kalateh Sadati ${ }^{2}$, Mohammad Hassan Rakhshani ${ }^{3}$
}

${ }^{1}$ M.Sc. in Midwifery, Department of Midwifery, Nursing and Midwifery school, Sabzevar University of Medical Sciences, Sabzevar, Iran

${ }^{2}$ Nursing B.Sc., Educational Hospital of Shahid Mobini Brothers, Sabzevar, Iran

${ }^{3}$ Ph.D. in Biostatistics, Department of Biostatistics, School of Public Health, Sabzevar University of Medical Sciences, Sabzevar, Iran

\section{Type of article: Original}

\begin{abstract}
Introduction: The neonatal mortality rate (NMR) is an essential index in the assessment of community health. With the rapid advancement of neonatal care, the causes of death in this group and the overall mortality rate have changed. For these reasons, the aim of this study was to determine the current NMR and its causes in Sabzevar City's Neonatal Intensive Care Unit (NICU).

Methods: This cross-sectional study was conducted in the NICU at Sabzevar Hospital from 2006 through 2013. Based on previous studies, the sample size was determined to be 365 neonates who were admitted to the NICU and died before they were discharged. The study tool was a researcher-developed checklist related to deceased neonates in the NICU. The checklist was confirmed based on the validity of its content and its inter-rater reliability. We used chi-squared, the Mann-Whitney U test, and the Spearman correlation to analyze the data.

Results: The NMR in Sabzevar's NICU was 6.44 per 1000 during the seven-year period; this rate included the following cases per 1000 live births: very early mortality (2.16), early mortality (3.33), and late mortality (0.96). Among 58,270 live births, 3,667 of the neonates were admitted to the NICU during the seven-year period, which was equivalent to 62.93 admissions per 1000 live births. Of the 3,667 neonates admitted to the NICU, 375 $(10.23 \%)$ died before they were discharged. The most recurrent diagnoses were respiratory distress syndrome $(46 \%)$, followed by sepsis $(12 \%)$. The one-sample chi-squared test as a goodness-of-fit test $(95 \% \mathrm{CI})$ showed that the mortality rates were significantly different based on gender $(p=0.004)$, birth weight $(p<0.001)$, gestational age $(\mathrm{p}<0.001)$, different causes of death $(\mathrm{p}<0.001)$, and different years of death $(2006-2013)(\mathrm{p}<0.001)$. There also was a significant difference between the duration of survival (very early mortality, early mortality, and late mortality) $(\mathrm{p}<0.001)$.

Conclusion: Neonatal mortality in the present study was comparable with that reported in similar studies in Iran and in other countries. The strong association between the mortality rate in the NICU with premature birth and low birth weight indicates the necessity of prenatal care aimed at preventing pre-term labor. Comprehensive programs from antenatal care and care at and after birth are recommended, including the investigation of the risks for neonatal death and offering preventive strategies
\end{abstract}

Keywords: neonatal mortality, neonatal intensive care unit, Sabzevar

\section{Introduction}

The neonatal mortality rate (NMR) includes deaths that occur at birth and up to 28 days after birth $(1,2)$, and NMR is an essential index in assessing health in a community $(3,4)$. The NMR in Iran is 12-15 per 1000 live births, whereas it is only about 5 per 1000 in developed countries (5). Neonatal mortality is divided into very early mortality (death in the first $24 \mathrm{~h}$ after birth), early mortality (death between one and seven days after birth), and late

\section{Corresponding author:}

Mohammad Hassan Rakhshani, School of Public Health, Sabzevar University of Medical Sciences, Sabzevar, Iran. Tel: +98.5144419573, E-mail: rakhshanimh75@gmail.com

Received: June 11, 2015, Accepted: October 17, 2015, Published: November 2015

iThenticate screening: July 16, 2015, English editing: August 23, 2015, Quality control: November 08, 2015

(C) 2015 The Authors. This is an open access article under the terms of the Creative Commons Attribution-NonCommercialNoDerivs License, which permits use and distribution in any medium, provided the original work is properly cited, the use is non-commercial and no modifications or adaptations are made. 
mortality (death between 8 and 28 days after birth) $(1,6)$. Very early neonatal mortality has the greatest incidence (4.27 per 1000 live births in 2008) (6). Generally, NMR accounts for about $67 \%$ of the total infant mortality rate, and reducing this rate is one of the government's growth and development criteria (7). Thus, one of the government's millennium development goals is to reduce the mortality rate of children under 5 years old in 2015 to two-thirds of the rate in 1990 (8). The total infant mortality rate has been reduced throughout the world, but neonatal mortality has been decreased less $(7,9)$.

A high rate of neonatal mortality occurs in NICUs, so periodic assessment of the practices of these units and making appropriate revisions in the practices can be effective in reducing the mortality rate (10). Reducing this rate is important from the healthcare perspective, but it also would result in economical, psychological, and social benefits that extend beyond the neonatal period to childhood, adolescence, and the entire lifetime (7). Certainly, the first step in reducing mortality is to determine the causes (8). Causes of neonatals' deaths generally are classified into two groups, i.e., biological causes and non-biological causes. The biological causes include pre-term birth; low birth weight (LBW), i.e., birth weight less than 2,500 g; and congenital anomalies. The non-biological causes include economic, social, and cultural factors $(5,6)$. Several studies have been conducted on neonatal mortality rate in NICUs and its related causes $(5,8,9,11)$. In 2011, Eman et al. reported that the NMR was 58.8\% in Egypt's NICUs. The significant risk factors associated with the neonatal deaths were vaginal delivery, multiple births, low Apgar score at the fifth minute, respiratory distress, premature birth, and LBW (9). In 2008, Mirza Rahimi et al. stated that the NMR in the NICUs of the hospitals associated with the Ardabil University of Medical Sciences in northwest Iran was $7.86 \%$ and that the most common factors were premature birth and LBW with Hyaline Membranes Disease (HMD) and sepsis being the most common causes of death (8). A 2010 study by Sereshtedari et al. reported an NMR of $22.2 \%$ in Qazvin, and the most common causes were sepsis and respiratory distress syndrome (RDS) (5). Reducing the NMR depends on preventing pre-term labor and LBW, prenatal diagnosis, and advanced care, including the use of corticosteroids, surfactants, and effective ventilation, as well as improving nutrition, early management of congenital anomalies, and timely and effective treatment of diseases in pregnancy and providing appropriate care during parturition $(6,12)$. With regard to rapid advances that have been made in neonatal care, changes have been observed in the NMR as well as the related causes (13).

The general objective of the research was to determine the NMR in the NICU in Sabzevar during the period of 2006-2013. The specific objectives of the study are listed below:

1) To compare different causes of mortality during the period of 2006-2013

2) To assess prevalence of mortality among the neonates admitted to the NICU based on gender, type of delivery, treatment with surfactant, birth weight (BW), duration of survival, and gestational age (GA) during the period of 2006-2013

3) To assess the effectiveness of the surfactant based on GA, BW, and the duration of survival

4) To determine the relationships between gender and GA, BW, and the duration of survival, as well as the relationships between the type of delivery and these same factors.

\section{Material and Methods}

\subsection{Research design and setting}

This cross-sectional study was conducted in the NICU at Shahid Mobini Brothers' Hospital in Sabzevar, Iran. This was the only hospital in Sabzevar City that had an NICU during the time of this study, 2006-2013.

\subsection{Sampling}

\subsubsection{Sample size}

Based on the statistical indices from previous studies (95\% CI and $9 \%$ neonatal mortality among admitted neonates in NICU, and $\mathrm{d}=0.025$ ) the appropriate sample size for this study was determined to be 353 .

\subsubsection{Sampling method}

In this cross-sectional study, the participants' data were gathered randomly from anytime in the past till acquiring the required number of samples. So, we included in this study all neonates who were admitted to the NICU from January 2006 to January 2013 and died before they were discharged from the hospital.

\subsection{Measurement tool and data collection}

The tool that was used in the study was a researcher-made checklist that included all neonates admitted to the NICU during the period of the study and all of the neonates among that group who died before they were discharged from the hospital. The content validity of the checklist and its inter-rater reliability was used to confirm its 
appropriateness. The checklist included various characteristics of the neonates, such as the type of delivery (vaginal or Caesarian section), GA, BW, single or multiple births, diagnoses of any diseases, the duration of survival, and treatment with surfactant. These checklists were completed by the researcher based on the available medical records. The birth rate was provided by the Statistics Department of the University.

\subsection{Ethical consideration}

This study was approved by the Research Committee of the Sabzevar University of Medical Sciences (Proposal reference no. 122.2954; Ethics committee code: medsab.Rec.92.21).

\subsection{Statistical analyses}

All data were gathered, coded, entered into a computer, and analyzed. Statistical analysis was performed using the Statistical Package for Social Sciences (SPSS), version 20. We used descriptive statistics and one sample chisquared tests, as well as U Mann-Whitney and Spearman tests to analyze the data. The significance level used was a P-value of less than 0.05 .

\section{Results}

During the seven-year period that was studied, 58,270 live births (an average of about 8324 live births per year) were recorded in the hospital. Of the 58,270 live births, 3,667 of them were admitted to the NICU, amounting to almost 63 cases per 1000 live births. Among the 3,667 neonates admitted to the NICU, 375 of them (10.23\%), i.e., 6.44 neonates per 1000 live births, died from various causes before being discharged from the hospital during the seven-year period of this study. Of the 375 neonates who died, 214 were males $(56.9 \%)$ and $43.1 \%$ were females. Of the 375 neonates who died in NICU, 46.3\% were delivered by C.S, and about $74.5 \%$ of them had birth weights less than 2,500 g. Among the 375 neonates who died before being discharged, 126 of them (33.5\%) died during their first day of life. In the following week, 194 (51.6\%) more of the neonates died, and within 1-4 weeks after birth, the remaining $56(14.9 \%)$ neonates died. So, on the basis of 1000 live births, the very early mortality rate ([of neonatal deaths in the first $24 \mathrm{~h}$ after birth/ total of live birth] x 1000) was 2.16, the early mortality rate ([of neonatal deaths 1 7 days/ total of live birth] x 1000) was 3.33, and the late mortality rate ([of neonatal deaths $8-27$ days/ total of live birth] x 1000) was 0.96 . Figure 1 shows the neonatal mortality rate of the NICU (Neonatal deaths in the NICU in each year/total live births in seven years) and gender-specific mortality (Neonatal deaths of a specific gender in the NICU each year/live births of the same gender in the same year). Figure 1 shows an increase in the rates and ratios beginning in 2010 .

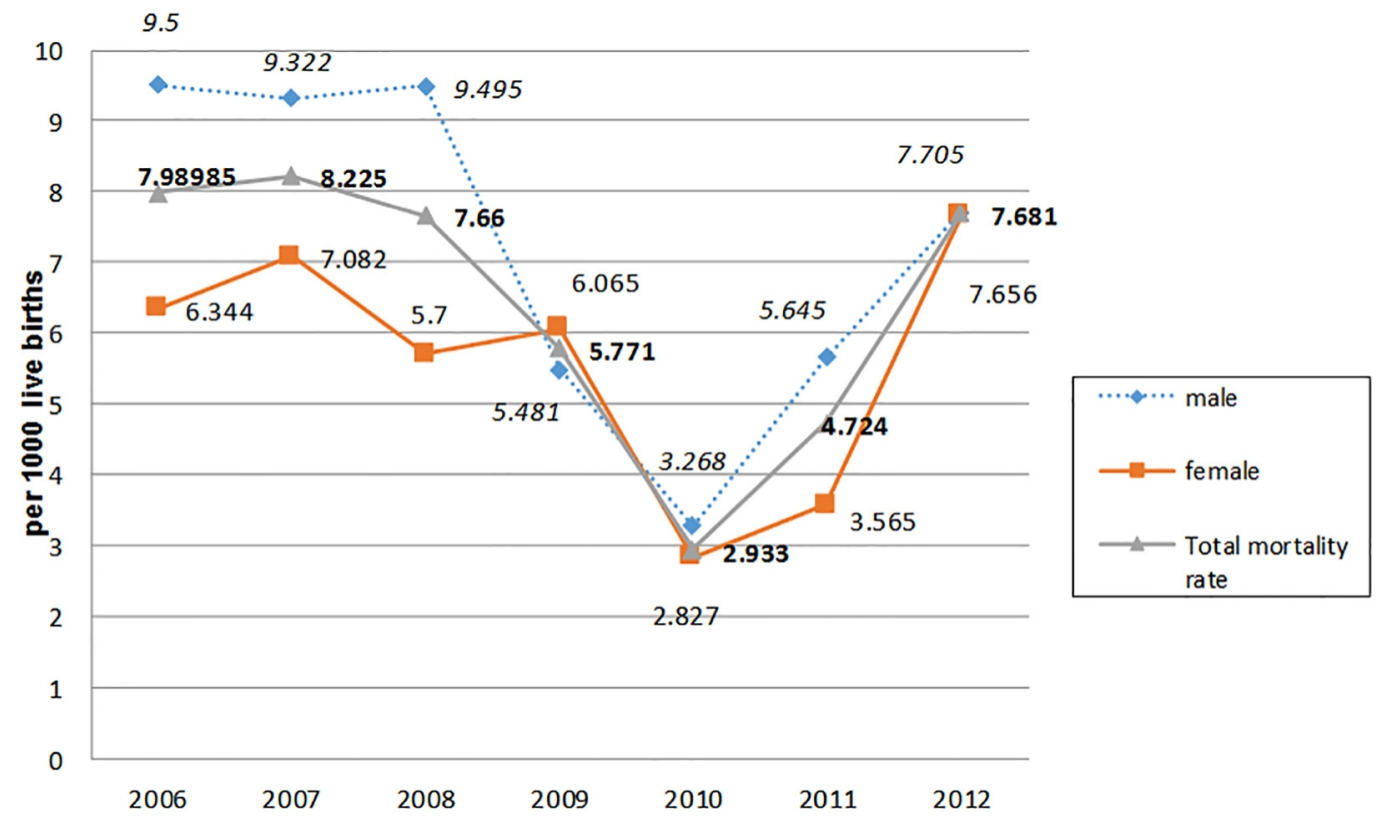

Figure 1. Neonatal mortality rate and gender-specific mortality in the NICU at Mobini Hospital in Sabzevar for the period of 2006-2013 
Among the causes of mortality, respiratory distress (46\%), sepsis (12\%), congenital anomaly $(9.8 \%)$, asphyxia $(8.5 \%)$, and pulmonary bleeding $(7.7 \%)$ constituted $84 \%$ of the causes of mortality in the seven-year period, which mostly increased in the two most recent years (data not in table). In contrast, the lowest prevalence causes of mortality included Necrotizing Enterocolitis (NEC) (1.1\%), metabolic syndrome (1.3\%), renal disease (1.3\%), meconial aspiration syndrome (1.6\%), and diaphragmatic hernia (1.6\%). Respiratory distress in 2012 was double that of 2010, and, since it was the most common cause of neonatal mortality $(46 \%)$ in the NICU, the rates and ratios that were mentioned were increased. However, the most number of births placed in 2010, while the number of deaths decreased. Then, in two later years, we observed a decrease in births and an increase in neonatal deaths in comparison to 2010, which influenced the rates and ratios. One-sample chi-squared as a goodness-of-fit test $(95 \%$ $\mathrm{CI})$ showed that the mortality rates were significantly different based on gender $(\mathrm{p}=0.004)$, BW $(<2500 ; \geqslant 2500 \mathrm{~g})$ $(\mathrm{p}<0.001)$, GA $(<34 \mathrm{w}, 34 \leqslant \mathrm{GA}<38 \mathrm{w}, 38 \leqslant \mathrm{GA} \leqslant 40 \mathrm{w})(\mathrm{p}<0.001)$, different causes of death $(\mathrm{p}<0.001)$, and different years of death $(2006-2013)(\mathrm{p}<0.001)$. Also, there was a significant difference between the duration of survival (very early death, early death, and late death) $(\mathrm{p}<0.001)$. Table 1 provides the frequency of the mortalities of the neonates admitted to the NICU during the period of 2006-2013.

Table 1. Frequency of mortality among the neonates admitted to the NICU at Mobini Hospital in Sabzevar for the period of 2006-2013

\begin{tabular}{|c|c|c|c|c|c|c|c|c|}
\hline \multirow{2}{*}{\multicolumn{2}{|c|}{$\begin{array}{l}\text { Year } \\
\text { Variables } \\
\end{array}$}} & \multicolumn{7}{|c|}{ Mortality Frequency } \\
\hline & & 2006 & 2007 & 2008 & 2009 & 2010 & 2011 & 2012 \\
\hline & Male & $\begin{array}{l}39 \\
(61.9 \%)\end{array}$ & $\begin{array}{l}40 \\
(57.1 \%)\end{array}$ & $\begin{array}{l}41 \\
(63.1 \%)\end{array}$ & $\begin{array}{l}23 \\
(46.9 \%)\end{array}$ & $\begin{array}{l}13 \\
(52 \%)\end{array}$ & $\begin{array}{l}25 \\
(62.5 \%)\end{array}$ & $\begin{array}{l}33 \\
(51.6 \%)\end{array}$ \\
\hline & Female & $\begin{array}{l}24 \\
(38.1 \%)\end{array}$ & $\begin{array}{l}29 \\
(41.1 \%)\end{array}$ & $\begin{array}{l}23 \\
(35.4 \%)\end{array}$ & $\begin{array}{l}25 \\
(51 \%)\end{array}$ & $\begin{array}{l}12 \\
(48 \%)\end{array}$ & $\begin{array}{l}15 \\
(37.5 \%)\end{array}$ & $\begin{array}{l}31 \\
(48.4 \%)\end{array}$ \\
\hline \multirow[t]{2}{*}{ Delivery type } & $\begin{array}{l}\text { Normal } \\
\text { Delivery }\end{array}$ & & & $\begin{array}{l}36 \\
(55.6 \%)\end{array}$ & $\begin{array}{l}25 \\
(57.1 \%)\end{array}$ & $\begin{array}{l}13 \\
(52 \%)\end{array}$ & $\begin{array}{l}23 \\
(57.5 \%)\end{array}$ & $\begin{array}{l}30 \\
(47.5 \%)\end{array}$ \\
\hline & $\begin{array}{l}\text { Cesarean } \\
\text { Section }\end{array}$ & & & $\begin{array}{l}29 \\
(44.6 \%) \\
\end{array}$ & $\begin{array}{l}21 \\
(42.9 \%) \\
\end{array}$ & $\begin{array}{l}12 \\
(48 \%) \\
\end{array}$ & $\begin{array}{l}17 \\
(42.5 \%) \\
\end{array}$ & $\begin{array}{l}33 \\
(52.4 \%) \\
\end{array}$ \\
\hline \multirow[t]{2}{*}{ Surfactant } & Yes & $\begin{array}{l}23 \\
(36.5 \%)\end{array}$ & $\begin{array}{l}38 \\
(54.3 \%)\end{array}$ & $\begin{array}{l}20 \\
(30.8 \%)\end{array}$ & $\begin{array}{l}26 \\
(53.1 \%)\end{array}$ & $\begin{array}{l}15 \\
(60 \%)\end{array}$ & $\begin{array}{l}23 \\
(57.5 \%)\end{array}$ & $\begin{array}{l}42 \\
(65.6 \%)\end{array}$ \\
\hline & No & $\begin{array}{l}40 \\
(63.5 \%)\end{array}$ & $\begin{array}{l}32 \\
(45.7 \%)\end{array}$ & $\begin{array}{l}45 \\
(69.2 \%)\end{array}$ & $\begin{array}{l}23 \\
(46.9 \%)\end{array}$ & $\begin{array}{l}10 \\
(40 \%)\end{array}$ & $\begin{array}{l}17 \\
(42.5 \%)\end{array}$ & $\begin{array}{l}22 \\
(34.4 \%)\end{array}$ \\
\hline \multirow[t]{2}{*}{$\begin{array}{l}\text { Birth Weight } \\
<2500\end{array}$} & Yes & $\begin{array}{l}44 \\
(69.8 \%)\end{array}$ & $\begin{array}{l}51 \\
(72.9 \%)\end{array}$ & $\begin{array}{l}48 \\
(73.8 \%)\end{array}$ & $\begin{array}{l}37 \\
(75.5 \%)\end{array}$ & $\begin{array}{l}19 \\
(76 \%)\end{array}$ & $\begin{array}{l}31 \\
(77.5 \%)\end{array}$ & $\begin{array}{l}50 \\
(78.1 \%)\end{array}$ \\
\hline & No & $\begin{array}{l}19 \\
(30.2 \%)\end{array}$ & $\begin{array}{l}19 \\
(27.1 \%)\end{array}$ & $\begin{array}{l}17 \\
(26.2 \%)\end{array}$ & $\begin{array}{l}12 \\
(24.5 \%)\end{array}$ & $6(24 \%)$ & $\begin{array}{l}9 \\
(22.5 \%)\end{array}$ & $\begin{array}{l}14 \\
(21.9 \%)\end{array}$ \\
\hline \multirow[t]{3}{*}{$\begin{array}{l}\text { Survival } \\
\text { Duration }\end{array}$} & $<1$ day & $\begin{array}{l}32 \\
(50.8 \%)\end{array}$ & $\begin{array}{l}31 \\
(44.3 \%)\end{array}$ & $\begin{array}{l}26 \\
(40 \%)\end{array}$ & $\begin{array}{l}7 \\
(14.3 \%)\end{array}$ & $9(36 \%)$ & $\begin{array}{l}11 \\
(27.5 \%)\end{array}$ & $\begin{array}{l}10 \\
(15.6 \%)\end{array}$ \\
\hline & $1-<7$ days & $\begin{array}{l}27 \\
(42.9 \%) \\
\end{array}$ & $\begin{array}{l}32 \\
(45.7 \%) \\
\end{array}$ & $\begin{array}{l}33 \\
(50.8 \%) \\
\end{array}$ & $\begin{array}{l}29 \\
(59.2 \%) \\
\end{array}$ & $\begin{array}{l}10 \\
(40 \%)\end{array}$ & $\begin{array}{l}20 \\
(50 \%)\end{array}$ & $\begin{array}{l}43 \\
(67.2 \%) \\
\end{array}$ \\
\hline & $1-<4$ weeks & $4(6.3 \%)$ & $7(10 \%)$ & $6(9.2 \%)$ & $\begin{array}{l}13 \\
(26.5 \%)\end{array}$ & $6(24 \%)$ & $\begin{array}{l}9 \\
(22.5 \%)\end{array}$ & $\begin{array}{l}11 \\
(17.2 \%)\end{array}$ \\
\hline \multirow[t]{3}{*}{$\begin{array}{l}\text { Gestational } \\
\text { age (week) }\end{array}$} & GA $<34$ & $\begin{array}{l}37 \\
(58.7 \%)\end{array}$ & $\begin{array}{l}44 \\
(62.9 \%)\end{array}$ & $\begin{array}{l}43 \\
(66.2 \%)\end{array}$ & $\begin{array}{l}34 \\
(69.4 \%)\end{array}$ & $\begin{array}{l}16 \\
(64 \%)\end{array}$ & $\begin{array}{l}28 \\
(70 \%)\end{array}$ & $\begin{array}{l}41 \\
(64.1 \%)\end{array}$ \\
\hline & $34 \leq \mathrm{GA}<38$ & $\begin{array}{l}7 \\
(11.1 \%)\end{array}$ & $\begin{array}{l}9 \\
(12.9 \%)\end{array}$ & $6(9.2 \%)$ & $1(2 \%)$ & $4(16 \%)$ & $1(2.5 \%)$ & $\begin{array}{l}7 \\
(10.9 \%)\end{array}$ \\
\hline & $38 \leq \mathrm{GA} \leq 40$ & $\begin{array}{l}19 \\
(30.2 \%)\end{array}$ & $\begin{array}{l}17 \\
(24.3 \%)\end{array}$ & $\begin{array}{l}16 \\
(24.6 \%)\end{array}$ & $\begin{array}{l}14 \\
(28.6 \%)\end{array}$ & $5(20 \%)$ & $\begin{array}{l}11 \\
(27.5 \%)\end{array}$ & $\begin{array}{l}16 \\
(25 \%)\end{array}$ \\
\hline
\end{tabular}

Table 2 shows the mean \pm S.E of some important variables, based on gender and the type of delivery, related to the neonates who died in the NICU. The Mann-Whitney test showed no significant relationships between GA, BW, and the duration of survival with gender and the type of delivery. The Mann-Whitney test indicated that surfactant was used more often with premature or LBW neonates and that it could increase the duration of survival. In other words, GA, BW, and the duration of survival were significantly different in neonates who received surfactant (all three 
variables, $\mathrm{p}<0.001)$. GA had a significant association with the duration of survival $(\mathrm{p}=0.002)$. Neonatal death occurred earlier when GA was decreased.

Table 2. Mean \pm S.E of important variables for the neonates who died in the NICU at Mobini Hospital in Sabzevar based on gender and the type of delivery

\begin{tabular}{|l|l|l|l|l|}
\hline \multirow{2}{*}{ Variables } & \multicolumn{3}{|l|}{ Mean \pm S.E } \\
\cline { 3 - 5 } & & Gestational Age (week) & Birth Weight (gram) & Survival Duration (hour) \\
\hline Gender & Male & $31.43 \pm 0.476$ & $1729.25 \pm 91.76$ & $100.27 \pm 10.21$ \\
\cline { 2 - 5 } & Female & $30.47 \pm 0.541$ & $1523.96 \pm 95.6$ & $97.08 \pm 10.75$ \\
\hline $\begin{array}{l}\text { Delivery } \\
\text { type }\end{array}$ & Normal Delivery & $30.92 \pm 0.529$ & $1730.62 \pm 99.291$ & $89.48 \pm 9.12$ \\
\cline { 2 - 5 } & Cesarean Section & $31.17 \pm 0.467$ & $1540.89 \pm 83.84$ & $108 \pm 11.85$ \\
\hline
\end{tabular}

\section{Discussion}

About $10.6 \%$ of the neonates admitted to the NICU at Mobini Hospital in Sabzevar City over a seven-year period, $10.6 \%$ died before they were discharged from the hospital. The NMR was higher in males, LBW, GA $<34$ w, early mortality, and among neonates who had respiratory distress. The application of surfactant increases the duration of survival. The NMR in the NICU at Mobini Hospital in Sabzevar City was lower than those observed in similar studies in Isfahan, Sari, and Qazvin $(1,5,7)$, but it was greater than the rate observed in Ardabil (8). The Ardabil study focused on neonates who were admitted to the normal neonates unit and the NICU, so it is obvious that the NMR in NICU would be higher it would be among neonates who did not have any physical complications. However, our study was conducted by considering a period of seven years with a larger sample size, which should improve the validity of the results. The NMR reported in our study was significantly lower than in some other countries, e.g., Egypt (9) and India (14), but it was still higher than some other countries, e.g., Canada (15).

Various factors affect NMR, such as GA, BW, and having diseases at birth NMR (1). The cut-off point for neonatal death was a BW of 2,500 g with a sensitivity of more than 70\% (9). The mean BW was $1635.75 \pm 91.56 \mathrm{~g}$ in this study. The risk of neonatal death is lower when GA and BW are higher (9). We stated that respiratory distress was the main cause of neonatal mortality (46\%) in our study, with sepsis in second place at $12 \%$. Both LBW and smaller GA had significant association with NMR, which was in agreement with Ardabil's findings [HMD (52.2\%) and sepsis (14\%) and smaller GA had a significant association with NMR] (8) and Qazvin's results [sepsis (40\%) and respiratory distress (26\%) and smaller GA had a significant association with NMR] (5).

Significant advances in the care provided NICUs, especially in developed countries, including the use of modern equipment, the administration of surfactant, and advanced care of pre-term neonates, have improved the prognosis for neonates who are admitted to the NICU. This may be a reason for differences in the neonatal mortality rates among the communities mentioned above (9). However, this study had some limitations, one of which was the lack of assessment of the neonates who had just been admitted to the NICU. In other words, we had not assessed neonates in other settings, so we may have missed some of the risk factors for neonatal mortality. Thus, we recommend that a study be conducted to assess neonatal mortality in all segments of society. One other limitation was the lack of information on the severity of diseases among the neonates because we had to use the available records, some of which were incomplete.

\section{Conclusions}

The findings of this study showed that 6.44 neonates died per 1000 births during the seven-year period of the study. Most of these deaths were due to respiratory distress, low birth weight, premature delivery, and sepsis. The strong association between the mortality rate in the NICU and low birth weight and premature birth indicated the necessity of prenatal care aimed at preventing pre-term labor. If there are any risks for the fetus or the mother, special care should be offered. The results of this study suggest that NMR committees should be established and charged with developing comprehensive programs for providing antenatal care through birth for the fetus and the mother, including the investigation of the risk of neonatal death and the provision of preventive strategies.

\section{Acknowledgments:}

The authors express their appreciation to Sabzevar University of Medical Sciences and Shahid Mobini Hospital of Sabzevar for granting us permission to gather the data we needed for the study. 


\section{Conflict of Interest:}

There is no conflict of interest to be declared.

\section{Authors' contributions:}

All authors contributed to this project and article equally. All authors read and approved the final manuscript.

\section{References}

1) Cunningham G, Leveno K.J, Bloom S.T, Spong C.Y, Dashe J.S, Hoffman B.L,et al. Williams obstetrics. 24th. New York: Mc Graw-Hill; 2014.

2) Bala Ghafari A, Siamian H, Aligolbandi K, Rashida S. Survey of characteristics of neonatal death in neonatal intensive care unit of Boo-Ali Sina educational \& therapeutic center between 2003-2006. J Mazand Univ Med Sci. 2009; 20(74): 79-83.

3) Chaman R, Holakouie Naieni K, Golestan B, Nabavizadeh H, Yunesian M. Neonatal Mortality Risk Factors in a Rural Part of Iran: A Nested Case-Control Study. Iranian J Publ Health. 2009; 38(1): 48-52.

4) Golestan M, Fallah R, Akhavan Karbasi S. Neonatal mortality of low birth weight infants in Yazd, Iran. Iran J Reprod Med. 2008; 6(4): 205-8 . DOI: 10.1016/j.earlhumdev.2008.09.065.

5) Sareshtedari M, Shahamat H, Sadeghi T. Causes and Related Factors of Neonatal Mortality in Qazvin NICU, 2010. Hakim Health Sys Res. 2012; 14(4): 227-32.

6) Behrman RE, Kligman R. Jenson H. Nelson Text book of Pediatrics. United States: Philadelphia; 2011.

7) Javanmardi Z, Beigi M, Nouhpisheh E, Memarzadeh M, Radan M R. The reported causes for neonatal death in hospitals of Isfahan province in 2005. IJNMR. 2008; 13(2): 87-9.

8) Mirzarahimi M, Abedi A, Shahnazi F, Sa'adati H, Enteshari A. Causes and Rate of Mortality among the Newborns in NICU and Newborns Unit at Ardabil hospitals. J Ardabil Univ Med Sci. 2009; 8(4): 424-30.

9) Mohamed EM, Soliman AMA, El-Asheer OM. Predictors of mortality among neonates admitted to neonatal intensive care unit in pediatric Assiut University Hospital, Egypt. J Am Sci. 2011; 7(6): 606-11.

10) Ghaffari Saravi V, Khani S, Kosarian M, Zaeri aqamshhady H. Predictive value of SNAP-PE, SNAP, CRIB indices for prediction of disease severity and determination of death in infants admitted to NICU. J Mazandaran Univ Med Sci. 2009; 19(73): 1-9.

11) Mohsen Zade A, Shah Karami K, Verkouhi A. KH. Assessment the characteristics of died neonates in NICU of Shahid Madani hospital of Khoramabad- Lorestan, 2002. (Abstract of the 5th International Congress on Pulmonary Diseases and Intensive Care). Available from: http://ganj.irandoc.ac.ir/articles/329722; accessed date: 1 Jan 2015.

12) Khani S, Mohammadpour Tahamtan R.A, Saravi V. Ghaffari, Abdollahi F, Sabbaghi R, Bavand M. Neonatal survival rate and its related causes in NICU of private and governmental hospitals in Sari by survival analysis technique during 2005-2007. J Mazandaran Univ Med Sci. 2008; 17(62): 54-62.

13) Kadivar M, Sagheb S, Bavafa F, Moghadam L, Eshrati B .Neonatal Mortality Risk Assessment in a Neonatal Intensive Care Unit (NICU). Iran J Ped. 2007; 17(4): 325-31.

14) Basu S, Rathore P, Bhatia BD. Predictors of mortality in very low birth weight neonates in India. Singapore Med J. 2008; 49(7): 556 -60. PMID: 18695864

15) Sankaran K, Chien LY, Walker R, Seshia M, Ohlsson A, Lee S. K, et al. Variations in mortality rates among Canadian neonatal intensive care units. CMAJ. 2002; 166(2): 173-8. PMCID: PMC99269. 